\title{
Medium and Small Investors Interest Protection: Why Am I the One Who Always Gets Hurt? - Case Study of Kang Zhi Pharmaceutical
}

\author{
Hangying Zou \\ Management School, Jinan University, Guangzhou, China \\ Email: zouhy1013@163.com
}

Received 18 April 2016; accepted 16 July 2016; published 19 July 2016

Copyright (C) 2016 by author and Scientific Research Publishing Inc. This work is licensed under the Creative Commons Attribution International License (CC BY). http://creativecommons.org/licenses/by/4.0/

(c) () Open Access

\begin{abstract}
To safeguard the legitimate rights and interests of medium and small investors is the basic premise of the stable development of the capital market, and is a powerful driving force to promote the improvement of capital market. However, with the rapid development of China's capital market, a series of major financial fraud cases of listed companies have occurred in succession. These events not only cause great negative impact on our country immature capital market, but also bring serious damage to the interests of medium and small investors. This paper takes the Kang Zhi pharmaceutical financial fraud case as an example, analyzing the root of the financial fraud and its impact on the interests of medium and small investors. Also, in order to improve the mechanism of corporate governance supervision, to improve the quality of intermediary, and to strengthen management of the capital market legal system, some suggestions are given.
\end{abstract}

\section{Keywords}

Kang Zhi Pharmaceutical, Financial Fraud, Medium and Small Investors, Protection of Interests

\section{Introduction}

In recent years, the financial fraud scandals of listing Corporation emerge in an endless stream. Following the case of Enron, Chinese concept stocks, green earth, purple Xin pharmaceutical, *ST Bo Yuan, Kang Zhi pharmaceutical and so on, have been charged of financial fraud. This series of events seriously harm the interests of medium and small investors. Wei Chen (2008) studied the equity transfer events in Shanghai and Shenzhen 
stock market in 1994-2003. He empirically tested whether the legal system of our country was perfect to protect medium and small investors. The study showed that after 2000, the legal protection gradually played a role and private benefits of controlling shareholders would continue to reduce [1]. Baochun Guo (2013) investigated the protection of medium and small investors from three fields of corporate governance, information disclosure and legal regulation. According to the results of the survey, information disclosure lacks of timeliness, reliability and decision-making relevance. Legal norms remain to be improved [2].

So, the case study on the protection of the interests of medium and small investors not only has rich theory value for enterprise risk management, but also helps to trigger more attention to the protection of the interests of medium and small investors.

\section{Case Review}

Kang Zhi pharmaceutical is the first GEM listed pharmaceutical company in Hainan Province, and is also currently the only one in the country that takes children's medicine industry as main industry, mainly engaged in research and development, manufacturing and sales business in the field of children's medicine. As one of the largest and the most efficient pharmaceutical companies in children's medicine field in recent years, Kang Zhi pharmaceutical long established "professional cooperation agency model" and "the third terminal marketing model", which has become the high barriers to competition. Kang Zhi pharmaceutical has gradually formed the core strengths of "well-known brand + agency model + deep into the grassroots".

However, in 2013, namely nearly three years after the GEM Listing, Kang Zhi pharmaceutical that was high hoped was real-name reported of financial fraud by the former director of the audit, who report the presence of inflated profit in 2011 to 2012, cosmetic results, illegal issuing VAT invoices, fictitious transactions, conceal affiliates and other major violations. The Commission has investigated. On July 2, 2014, Kang Zhi pharmaceutical issued a statement, admitting two illegal facts of confirming sales revenue in advance and inflating profit. The inflated profit is respectively 238 million and \$231 million in 2011 and 2012. Kang Zhi pharmaceutical accepted the punishment of the Commission.

Kang Zhi pharmaceutical financial fraud, once again let the majority of investors to be discouraged. Listed company's financial fraud cases are common, repeated penalties for repeat offenders, which make small and medium investors not only lose money and material, but also lose confidence on China's securities market integrity. So in the end who is damaging the interests of small and medium investors?

\section{Case Analysis: Who Hurt the Legitimate Interests of Small and Medium Investors?}

\subsection{The Listing Corporation Harm Investor Interests in Order to Gain the Trust of the Investors}

\subsubsection{Confirm Sales Revenue in Advance}

The star product of Kang Zhi pharmaceutical is Ruizhi Qing, whose main components are nimesulide. Its sales revenue is the main source of main business income and profits for Kang Zhi pharmaceutical. Ruizhi Qing sales revenue amounted to 1.7 billion yuan and 2.2 billion yuan in 2009 and 2010, which was the only one whose sales revenue amounted to billions in company. The proportion that annual sales revenue of Ruizhi Qing accounted for the same period company main business revenue was $73.01 \%, 80.77 \%$ and $72 \%$, respectively, in 2008-2010. It can be said that the condition of Ruizhi Qing production and sales determines the profit level of Kang Zhi pharmaceutical. However, as the public questioned the efficacy of nimesulide and the food and drug administration issued ban notice, Kang Zhi pharmaceutical who originally had a good report card was caught in the deadly storm just six months after the listing. Ruizhi Qing sales suffered a disastrous decline. In order to relieve the impact of Ruizhi Qing events on the performance of the company, Kang Zhi pharmaceutical began to vigorously promote new products, Dulailin. And "the OTCco promotion Agreement" was signed with Yunnan Wan Cui Pharmaceutical. However, the introduction of new products did not play a substantial role in the company, but brought a more serious impact on the corporation performance. To cover the decline in performance caused by drug Ruizhi Qing and Dulailin, before Kang Zhi pharmaceutical performed obligations of putting on the ads in accordance with" the OTCco promotion Agreement, Kang Zhi pharmaceutical confirmed 340000 boxes Dulailin sales to Yunnan Wan Cui according to the "product purchase and sales contracts" in advance. 
Kang Zhi pharmaceutical inflated approximately \$250 million sales revenue and then inflated 157 million yuan profits.

\subsubsection{Hidden Related Party Transactions}

"Accounts receivable" and "other receivables" are the most convenient for financial fraud, which are known to be the largest source of false accounts. In order to raise the annual profit, listing corporation can carry on credit transactions with affiliated enterprises. The credit transaction between associated enterprises does not produce cash flow, and will only affect the balance sheet and income statement. So in the cash flow statement credit transaction will not be reflected. In the financial statements of the listing corporation in China, "accounts receivable" and "other receivables" remain stubbornly high. However, it is very few that "accounts receivable" and "other receivables" are identified the fraud. Yugui Hao (2012) analyzed the case of purple Xin pharmaceutical and pointed out that the use of related party transactions, is the main means of financial fraud. [3] According to the data of the financial statements before the update, in 2011, Kang Zhi pharmaceutical accounts receivable increased by $135.34 \%$ compared to 2010. Among them, the accounts receivable amount of Guangdong Daxiang Pharmaceutical is the largest, accounting for the total accounts receivable $46.31 \%$. And the proportion is nearly 13 times as much as Guangdong Heng Dongyuan Pharmaceutical that ranked second. As shown in Figure 1, in 2010 and 2012 the proportion of Guangdong Daxiang are respectively 18.06\% and 13.34\%.But in 2011 the proportion reached $46.31 \%$. The proportion experienced a substantial increase and then a large decline, which make people puzzled. This is reminiscent of whether Kang Zhi pharmaceutical and Guangdong Daxiang has certain connection. And among those who receive illegal VAT invoices issued by Kang Zhi pharmaceutical , the amount of Guangdong Daxiang received is large.

To compensate for the sales revenue plummeting caused by Ruizhi Qing events and cover poor sales of main medicines Dulailin, Kang Zhi pharmaceutical company try to restore the confidence of investors by the fictitious sales of other varieties and the inflated sales revenue. However, this remedial actions at the expense of damaging the interests of the investors caused great negative impact on healthy development of listed companies and the capital market.

\subsection{Relevant Intermediaries Haven't Pay Enough Attention to Protecting the Interests of Medium and Small Investors}

\subsubsection{Intermediaries Do Not Carry out Their Duties Diligently}

From the choice of IPO projects, listing guidance, to continuous supervision after the listing, intermediaries play a key role for company listing. Study on *ST Bo Yuan by Xiang Xu (2015) reveals the accounting firms should be responsible for disclosing false financial report [4]. In securities issuance market every intermediary institution perform its own functions, auditing and investigating information disclosed by listed company according to their professional knowledge, respectively, so that investors are less subject to false information misleading. In this way we can weaken the degree of information asymmetry between listed companies and investors. Thus, intermediaries act as "gatekeeper" for the capital market. However, the intermediaries also face the principal-

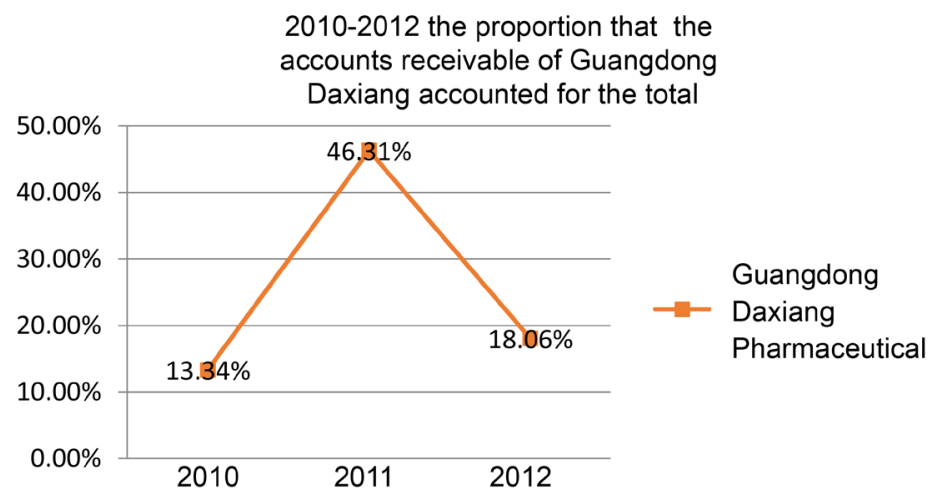

Figure 1. 2010-2012 the proportion that accounts receivable of Guangdong Daxiang accounted for total accounts receivable. 
agent problem because there are potential conflicts of interest between the agency and the principal. When interests of issuer and investors collide, the dual identity of intermediaries will inevitably be in a dilemma about how to balance them. As information vulnerable groups in the capital market, medium and small investors identify the credibility of relevant information for investments, largely depending on professional certification by intermediaries. Once the intermediaries were lost in the game among the interests of all aspects and lose the function of auditing listed company information impartially, the medium and small investors would be easily cheated by listed companies. In Kang Zhi pharmaceutical fraud case, the deadline of the continuous supervision of Haitong Securities should be December 31, 2013. However, there has been a serious financial fraud for Kang Zhi pharmaceutical in 2011 and 2012 years. Obviously, Haitong Securities did not fully perform their respective responsibilities during the period of continuous supervision and guidance.

\subsubsection{Be Punished Too Lightly by Government Regulators}

Although the intermediary (Haitong Securities) and Accounting Firm (Zhong Shen Ya Tai) need to bear unshirkable responsibility to Kang Zhi pharmaceutical events, but other relevant departments also have the corresponding responsibility. Capital market irregularities punishment by our country government regulators is too light. As for the event of the Kang Zhi pharmaceutical, securities regulatory bureau decided to give them a warning and impose a fine of 35 million yuan to the enterprise, to give a warning and impose a fine of 10 million yuan to the chairman, Jiangyou Hong. Also, the vice president, Jiangtao Hong, and CFO, Huiliang Liu, were subject to the appropriate punishment. Such punishment was too light for the losses suffered by investors, so the announcement caused the strong dissatisfaction of a large number of small and medium investors. In addition, the audit institutions, Zhong Shen Ya Tai accounting firms, which was hired by Kang Zhi pharmaceutical, also was not punished in the event. The punishment imposed by relevant departments on the listed company's financial fraud was too light, which reduced the cost of illegal listed companies.

\subsection{The Time for Judiciary Investigation and Claim Is Too Long}

\subsubsection{Investigation Is Slow}

In the stock market, insider trading and stock manipulation and other illegal ACTS are nothing new now. The investigation and treatment of these disciplinary events by the justice department always seem to be slower. The period from irregularities investigation to the issue of punishment announcement tends to last longer. In addition, the state restrictions on violations presents obvious lag. For the Kang Zhi pharmaceutical event, people started to question its problems as early as 2012. But it was not investigated until the company was real-name reported in 2013. After a year, Kang Zhi pharmaceutical inflated profits charges were filled. At the same time, the limited number of investigators and high cost of investigation, resulted in that some market irregularities failed to get the investigation and handling in a timely manner. Although punished by the announcement of the securities regulatory bureau of Hainan, Kang Zhi pharmaceutical industry still had a lot of illegal suspects. Especially, whether its forged seal had direct relationship with inflated profits has not been verified. The suspect that has not been verified, probably in the future bring more benefit loss to small and medium investors. Judicial authorities currently face many difficulties in the process of the investigation. So illegal offender has fluky psychology, which increase the likelihood that medium and small investors' interests are violated.

\subsubsection{Claim Slowly-Abuse of Jurisdiction Objection}

Even if investor claims cases are common in our country capital market, but the road to claim are difficult and time-consuming. For example, Green earth company is caught in false statement claims by investors. This case of a civil claim is still in the process of trial. After the listing corporation was sued by investors, it often delay time by filing jurisdiction objection. Kang Zhi pharmaceutical industry is no exception. As the first case of civil claims lawsuit for "false statement of securities liability disputes", Kang Zhi pharmaceutical has attracted people from all walks of life to the fierce discussion on protecting medium and small investors' benefit. Kang Zhi pharmaceutical investors rights protection case has been opened a court session on April 8in Haikou. Although the earlier cases have experienced that the objection to the jurisdiction of the first trial, the second trial were dismissed by the Haikou intermediate people's court and the high court in Hainan, the Kang Zhi pharmaceutical filed objection to the jurisdiction again. This largely caused litigation delay and had a negative effect on the prosecution rights protection. At the same time, it also gave the defendant listed companies the opportunity to 
remedy. Quite a number of small and medium investors gradually gave up the opportunity to seek reimbursement from listed companies during the long wait of litigation.

\section{Case Study: How to Protect the Interests of Small and Medium Shareholders}

\subsection{Improve the Corporate Governance Mechanism}

Firstly, establish a standardized corporate governance system. Companies should clearly define the rights and obligations for board of shareholders, board of directors, board of supervisors and establish and improve the independent director system. Board of directors and senior management are supervised by the board of supervisors and independent directors. Secondly, strengthen the construction of corporate governance structure and establish and improve the accountability system of decision-making errors. Through the strengthening of internal governance, the corporation can enhance the effectiveness of governance and then promote the healthy development of enterprises. In addition to the audit committee, the internal audit institutions should be set up to improve the ability of self-inspection of enterprises. Also, improve the moral and professional quality of the grass-roots financial staff, so that they start from their own to eliminate illegal behavior, and actively report violations of enterprises. From the source of governance to prevent risks, we can guard against a series of infringement of interests from the listing corporation financial fraud at a smaller cost. Therefore, improving the corporate governance mechanism for the protection of the legitimate interests of small and medium investors is of great significance.

\subsection{Improve the Overall Quality of Intermediary Institutions}

History of the development of the capital market tells us that the participation of intermediary organizations expand the scale of the stock market, reduce the information asymmetry between the main body and play an important role on the development of the capital market. The objective and accurate opinions of intermediaries, not only reduce investors information collection cost and transaction cost, but also improve the information disclosure transparency and safety. And then it can reduce the cost of government supervision, improve the efficiency of supervision so as to promote efficient operation of the capital market. Intermediaries are the main force to ensure the veracity of the securities information and protect investors interests. But profit is also the basic premise for all intermediaries to fulfill information assurance obligations. So it is not uncommon that the intermediaries lose in commission between the public interests and the client interests. In this regard, on one hand, strengthen impartiality, objectivity and independence of the intermediary institutions to adapt to requirements of the securities market, and on the other hand, how to deal with the relationship between the intermediary interests and customers interests directly affects the stability and development of the securities market. In addition to improving the relevant laws and regulations, more important is to improve the level of overall quality of intermediaries and maintain the independence of the intermediaries. Furthermore, we should establish intermediaries ongoing investigation and supervision system and improve intermediaries examination mechanism to promote it to play regulatory role well.

\subsection{Strengthen the Legal Management of Capital Market}

Yanyan Wang (2006) points out that the basic function of the independent audit is to provide protection for investors, but the realization of the function of the investor protection needs the corresponding legal environment as a guarantee. Through the model analysis, this paper introduces the legal factors and the independent variables of accountants into the investor protection, and examines the relationship between the legal environment, audit independence and the protection of investors. The research results show that: the legal protection of investors is the first for investor protection; independent audit is the second, when legal environment is relatively weak, which can act as legal alternative mechanism for investors to provide protection [5]. First, it investigates illegal cases strictly, and then reduces the number of illegal enterprises from the source. For illegal cases that have been filed, justice department shall carefully examine the prosecution materials, and then in a timely manner carry out comprehensive and in-depth investigation to shorten the time of forensics, and reduce the cost of the investigation. Only in this way, we can better safeguard the parties legitimate rights and interests. Secondly, it increases the intensity of the punishment of illegal enterprises and improves the cost of illegal acts. And even for the illegal behavior that results in serious consequences, justice department composes certain criminal responsibility. Finally, it guides people to fill litigation for his interests actively. If the victims are skeptical for legal supervi- 
sion and choose not to look into legal responsibility, then damaged interests of investors are difficult to get compensation. The government should develop education about protecting the rights and interests to guide medium and small investors to actively protect their own interests.

\section{References}

[1] Chen, W., Kong, X. and Xu, N.X. (2008) An Empirical Test on the Relationship between the Legal Protection of Small Investors and the Private Benefit of Control Right in China. China Industrial Economy, 2, 24-31.

[2] Guo, B.C. and Xu, L. (2013) The Protection of Medium and Small Investors: Current Situation and Countermeasures. Contemporary Accounting Review, 5, 52-67.

[3] Hao, Y.G. and Liu, L.X. (2012) The Internal Control and Audit of The related Party Transaction Fraud Risk: A Case Study of the Zi Xin Pharmaceutical Industry. Audit and Economic Research, 27, 26-35.

[4] Xu, X. (2015) Reflection and Enlightenment from the Financial Affairs of *STBo Yuan. Finance and Accounting, 11, 33-34.

[5] Wang, Y.Y. and Yu, L.S. (2006) Legal Environment, Audit Independence and Investor Protection. Finance and Trade Economics, 5, 32-38.

\section{Submit or recommend next manuscript to SCIRP and we will provide best service for you:}

Accepting pre-submission inquiries through Email, Facebook, Linkedin, Twitter, etc A wide selection of journals (inclusive of 9 subjects, more than 200 journals)

Providing a 24-hour high-quality service

User-friendly online submission system

Fair and swift peer-review system

Efficient typesetting and proofreading procedure

Display of the result of downloads and visits, as well as the number of cited articles

Maximum dissemination of your research work

Submit your manuscript at: http://papersubmission.scirp.org/ 